\title{
Proceeding
}

8th INSHS International Christmas Sport Scientific Conference, 5-7 December 2013. International Network of Sport and Health

Science. Szombathely, Hungary

\section{The development of students' information potential on the base of video project creation}

\author{
EKATERINA DYTKO , NATALIA.ERSHOVA \\ ${ }^{1}$ V.L. Sports Academy, Russia
}

\begin{abstract}
Dytko, E. \& Ershova, N. (2014). The development of students' information potential on the base of video project creation. J. Hum. Sport Exerc., 9(Proc1), pp.S232-S235. The problem of the development of information potential in sports higher educational establishments is a widely-discussed one. Scientific ideas concerned with foreign languages, must be specially fixed, transformed and spread. This principle is observed when dealing with video projects. A video-based project is defined by scholars as a means of the elimination of language obstacles, a strong motivating factor in language learning and a powerful resource of information potential development. The measurements of students' motivation level before the project have shown a low interest rate to learning the English language while after the project the students' use of speech patterns within the compiled material has increased. The video project was presented at the 16th Festival of sports higher educational establishments in nomination "Lingua" (Smolensk, 2013) and awarded the first place in the nomination. Being a combination of audio and visual information, a film is a multimeans helping to motivate students to search for the most adequate ways of getting new knowledge extracting it from video episodes and using it to understand all possible aspects of culture and education. This brings the information potential of an individual to a higher scale which he used to have before taking part in a video project. Key words: INFORMATION SOURCES, MOTIVATION, LANGUAGE LEARNING
\end{abstract}

Corresponding author. V.L. Sports Academy, Russia.

E-mail: kylie.89@bk.ru

8th INSHS International Christmas Sport Scientific Conference, 5-7 December 2013. International Network of Sport and Health Science. Szombathely, Hungary.

JOURNAL OF HUMAN SPORT \& EXERCISE ISSN 1988-5202

(c) Faculty of Education. University of Alicante

doi:10.14198/jhse.2014.9.Proc1.03 


\section{INTRODUCTION}

The problem of the development of information potential in sports higher educational establishments is a widely-discussed one. Scientific ideas concerning with foreign languages, must be specially fixed, transformed and spread. This principle is observed when dealing with video projects. The teacher of English tries to enable his students to think in a more creative way, only suggesting a path or an idea which the students then rework into a fully-fledged project, a film that can be used in the analysis of the results of learning activity (Chard, 2001).

\section{MATERIAL AND METHODS}

\section{Participants}

The subjects were 20 students (10 females and 10 males) of Velikie Luki State Academy of Physical Education and Sports (age 18-22) with intermediate - upper intermediate English language knowledge.

\section{Measures}

The investigation was based on questionnaire revealing the information necessities of Internet users and video project analysis in which the above mentioned students took part.

\section{Procedures}

Firstly, the students for the investigation were chosen on the basis of their achievements in the English language during the 2012/13 academic year and their marks for the exams.

Secondly, the subjects of investigations were given the questionnaire on their motivation level, their results being carefully analyzed and reviewed for planning and making up the script of the video project and role distribution.

Thirdly, the results of student activity after the project were analyzed and carefully reviewed to make a conclusion on the development of their motivation level.

\section{Analysis}

The measurements of students' motivation level before the project have shown a low interest rate to learning the English language - 40 per cent of students were indifferent to the participation in the project (and their results of academic achievements were average), 60 per cent of students involved in the project showed good motivation level (their results of academic achievement being good or excellent). While participating in the project and getting more interested in it the students tried to do their best to present their language and artistic skills in a positive light. After the project the students' use of speech patterns within the compiled material has increased, as well their motivation level - the previous ratio 40 to 60 per cent has changed to 10 and 90 (10 disinterested subjects and 90 highly motivated and interested ones).

The video project was presented at the 16th Festival of sports higher educational establishments in nomination "Lingua" (Smolensk, 2013) and awarded the first place in the nomination. 


\section{RESULTS AND DISCUSSION}

A video-based project is pointed out by scholars as a means of language obstacles elimination, a strong motivating factor in language learning and a powerful resource of information potential development (Gasparyan, 2012).

The information potential level of different students in this respect seems to come gradually to the same stable point because many different factors are taken into consideration - professional situations of communication, the peculiarities of cross-cultural communication, active hearing, nonverbal communication and many others (Bekasova, S.N., 1999).

The group of 20 students of $2 n d, 3 r d$ and 4 th years of studying (the subjects of our research) under the guidance of the chair of foreign languages of Velikie Luki State Academy of Physical Education and Sports participated in the 16th Russian Festival of sports educational establishments in nomination "Lingua" which was held in September, 2013 in Smolensk. The team of Velikie Luki Sports Academy was awarded the first place for the video project under the name "Heading for Sochi-2014".

The participation in this nomination this year implied a presentation of a video project covering the topic of the forthcoming 22nd Winter Olympic Games in Sochi. This task demanded a very careful choice of language means, special lexical units and set expressions. Before getting ready to make a film project we have measured the subjects' motivation level and with the help of a questionnaire (Antipova, V.B.) and the same procedure was performed after the shooting process was over. These two measurements have shown that at first $40 \%$ of the subjects had very little interest in being involved in shooting and in the coming Olympics, compared to $60 \%$ of subjects who were very eager to show their artistic abilities and knowledge of English. The shooting process has made a significant change in students' motivation level because every day they gradually became more involved into the idea of unity and presenting the Sports Academy in the limelight. After the working process was over, the second motivation measurement has revealed that the initial ratio has changed into $80 \%$ of involved students compared to $20 \%$ of indifferent ones.

\section{CONCLUSIONS}

In the process of professionally-oriented interactive learning a lot of language obstacles are easy to overcome, the atmosphere of cooperation and mutual aid appears, the motivation and readiness to a more profound language learning are being formed, backed up by positive emotions and interest. Having a various didactic potential, the creation of video projects used in a foreign language course within the frames not only of foreign language classes but within the variety of cultural and sports festivals is not only one of the most important means of learning-cognitive activities of students but also the method of independence, creativity, self-actualization development.

Being a combination of audio and visual information, a film is a multi-means helping to motivate students to search for the most adequate ways of getting new knowledge extracting it from video episodes and using it to understand all possible aspects of culture and education. This brings the information potential of an individual to a higher scale which he used to have before taking part in a video project. 


\section{REFERENCES}

1. Bekasova, S.N. (1999). Information necessities as a factor of professional and personal development: on the base of the cycle of pedagogical disciplines. - Abstract of a thesis of applicant for a candidate degree on pedagogical sciences. - Saint-Petersburg, 1999.

2. Diane Curtis (2001). Project-Based Learning: Real-World Issues Motivate Students. http://www.edutopia.org/project-based-learning-student-motivation.

3. Gasparyan, L.A. (2012) Student video based project as a means of foreign language dialogic skills development. Pedagogical education in Russia, 3, pp.80-86.

4. Makurin A. (2013). Test: what motivation level do you have? http://antonmakurin.ru/blog/articles/article_51.html. 